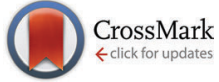

Cite this: Phys. Chem. Chem. Phys., $2016,18,26161$

Received 18th June 2016, Accepted 18th August 2016

DOI: $10.1039 / c 6 c p 04278 c$

www.rsc.org/pccp

\section{Generation and characterization of the phenylthiyl radical and its oxidation to the phenylthiylperoxy and phenylsulfonyl radicals $\dagger$}

\author{
Artur Mardyukov and Peter R. Schreiner*
}

The phenylthiyl radical (1) was prepared in the gas phase by vacuum flash pyrolysis of allylphenyl sulfide or diphenyl sulfide and isolated in an argon matrix. The hitherto unknown phenylthiyl peroxy radical was synthesized by co-condensation of 1 with molecular oxygen. Irradiation with light of $\lambda=465 \mathrm{~nm}$ led to a rearrangement to the novel phenylsulfonyl radical.
Sulfur-centred radicals are key reactive intermediates in chemistry ${ }^{1,2}$ and biology $;^{3,4}$ they typically form in a variety of light or heat initiated reactions of $\mathrm{S}-\mathrm{H}$ or $\mathrm{S}-\mathrm{S}$ bond cleavages of their precursors. $^{5-7}$ The simplest aromatic species, the phenylthiyl radical (1, Scheme 1), participates as a short-lived species in several reactions in the condensed phase. ${ }^{1,7,8}$ The most useful synthetic applications of the phenylthiyl radical draw on its ability to readily add to carbon-carbon multiple bonds; ${ }^{9-12}$ such additions have been intensively studied by Ito and co-workers. ${ }^{7,13-19}$ Radical 1 has also been used for the synthesis of natural products: $:^{20}$ for instance, Knapp and co-workers ${ }^{21}$ reported on a total synthesis of griseolic acid B that involved the free-radical addition of thiophenol to a sterically hindered enol ether moiety.

Despite its relevance to a variety of processes, only four low IR bands of $\mathbf{1}$ have recently been reported. ${ }^{22}$ Radical $\mathbf{1}$ was thereby generated by UV irradiation of thiophenol in a solid argon matrix, resulting in a mixture of compounds with $\mathbf{1}$ being the minor isomer. The absorption spectrum of $\mathbf{1}$ exhibited a strong band at $\sim 290 \mathrm{~nm}$ that did not reveal vibronic features. ${ }^{23}$ Pulse radiolysis of thiophenol in aqueous solution also led to 1 , with broad transitions at 295 and $460 \mathrm{~nm} \cdot{ }^{24}$ Radical 1 was also investigated by time-resolved resonance Raman spectroscopy, ${ }^{25}$ which revealed that the $\mathrm{C}-\mathrm{S}$ bond in $\mathbf{1}$ has single bond character with the unpaired electron localized on sulfur. The EPR spectrum of $\mathbf{1}$ has also been reported in glassy matrices at low temperatures. ${ }^{26,27}$

The experimental S-H bond-dissociation energy (BDE) of thiophenol was obtained using three different methods, i.e., via the electrochemical cycle (EC) method by Bordwell and Cheng, ${ }^{28}$ using an electron-transfer equilibration approach by

Institute of Organic Chemistry, Justus-Liebig University, Heinrich-Buff-Ring 17, 35392 Giessen, Germany. E-mail: prs@uni-giessen.de

$\dagger$ Electronic supplementary information (ESI) available. See DOI: $10.1039 / \mathrm{c} 6 \mathrm{cp} 04278 \mathrm{c}$

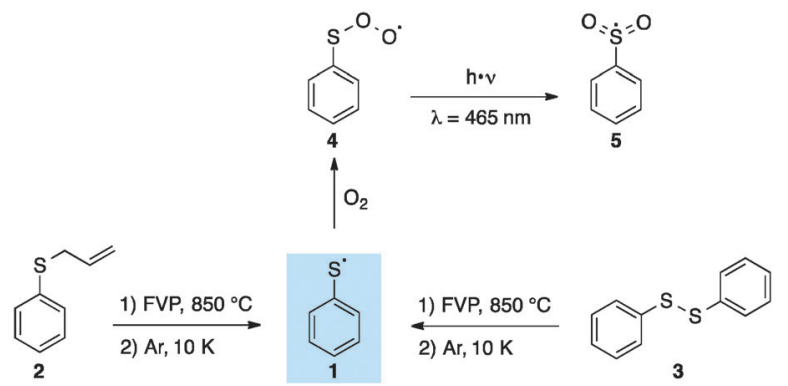

Scheme 1 The phenylthiyl radical (1) generated from either allylphenyl sulfide (2) or diphenyl disulfide (3) via VFP and trapping in an Ar matrix.

Armstrong et al., ${ }^{29}$ and by utilizing photoacoustic calorimetry by Borges dos Santos et al. ${ }^{30}$ The BDEs derived from these methods are 79.5, 80.4, and $83.9 \mathrm{kcal} \mathrm{mol}^{-1}$, respectively. The results of recent computations by Chandra $e t a l$. nicely reproduced the $\mathrm{BDE}_{\mathrm{S}-\mathrm{H}}\left(79.5 \pm 1 \mathrm{kcal} \mathrm{mol}^{-1}\right)$ at the B3LYP/6-311++G(2df,2p) level of theory. ${ }^{31}$

The reactions of thiylperoxy radicals have been the subject of numerous studies because of their involvement in organic synthesis ${ }^{1,8}$ and atmospheric transformations. ${ }^{32-36}$ Tan and Wille have shown the oxidation of bis-aromatic alkynes to $\alpha$-diketones by intervention of thiyl peroxy radicals formed through the reaction of thiyl radicals with molecular oxygen. ${ }^{8}$ A series of thiyl peroxy radicals were studied in detail by low temperature ESR. ${ }^{37-42}$ Zhang et al. studied the formation kinetics of thiylperoxy radicals by pulse radiolysis techniques. ${ }^{43}$

In this paper, we report new and efficient pathways for the generation and matrix isolation of $\mathbf{1}$ by vacuum flash pyrolysis (VFP) of allylphenyl sulfide (2) and diphenyl disulfide (3) in argon at $10 \mathrm{~K}$ and we reveal the most comprehensive IR data and band assignments to date. We also described the formation of a novel phenylthiyl peroxy radical (4) through a gas phase reaction of $\mathbf{1}$ with molecular oxygen and subsequent trapping in 


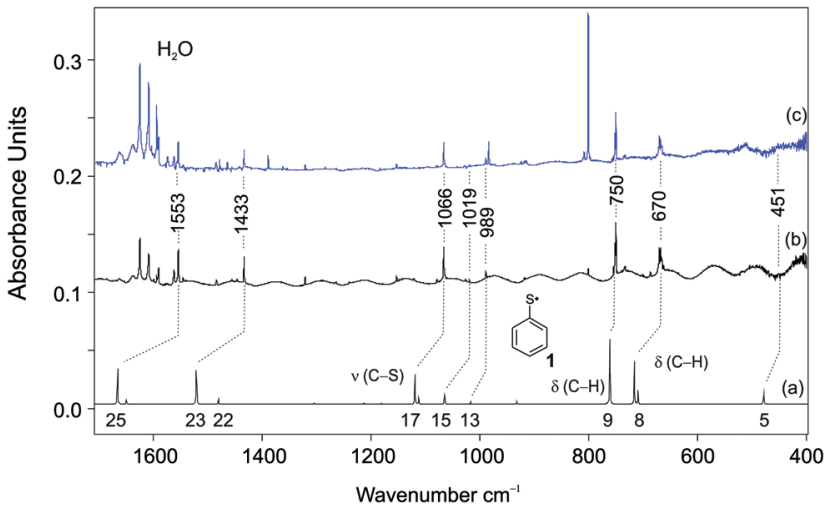

Fig. 1 (a) IR spectrum of 1 computed at M06-2X/6-311++G(2d,2p) (unscaled). (b) IR spectrum of the matrix-isolated pyrolysis products of diphenyl sulfide (3) in $\mathrm{Ar}$ at $10 \mathrm{~K}$; pyrolysis temperature: $850{ }^{\circ} \mathrm{C}$. (c) IR spectrum of the matrix-isolated pyrolysis products of allylphenyl sulfide (2) in $\mathrm{Ar}$ at $10 \mathrm{~K}$; pyrolysis temperature: $850^{\circ} \mathrm{C}$. Bands attributed to the allyl radical are marked with an asterisk $\left(^{*}\right)$.

argon matrices at $10 \mathrm{~K}$. The peroxy radical 4 can be photochemically rearranged into the considerably more stable equally novel phenylsulfonyl radical (5).

Radical 1 was generated under matrix isolation conditions from 2 or 3 as VFP precursors (Scheme 1). The IR spectrum of 1 matrix isolated in argon at $10 \mathrm{~K}$ obtained by VFP of 2 at $850{ }^{\circ} \mathrm{C}$ with subsequent trapping with an excess of argon is shown in Fig. 1 . In the case of 2 , VFP gave 1 and the allyl radical $\mathbf{6}$, while the precursor $\mathbf{3}$ predominantly yielded $\mathbf{1}$.

The excellent agreement between the experimental and unscaled M06-2X/6-311++G(2d,2p) as well as B3LYP/cc-pVTZ computed IR spectra is taken as evidence for the preparation of 1 (Fig. 1 and Fig. S1, ESI $\dagger$ ). The most prominent IR bands attributed to 1 at 750 and $670 \mathrm{~cm}^{-1}$ are also found in the precursors 2 and 3 and are thus assigned to the $\mathrm{C}-\mathrm{H}$ out-ofplane vibrational modes of the phenyl ring $\left(\nu_{8}\right.$ and $\left.\nu_{9}\right)$. The observed splitting of the vibrational bands is likely due to the different trapping sites in the argon matrix, which is a common phenomenon. ${ }^{44}$ With the aid of the computations, the additional other intense IR bands of medium intensity at 1553, 1433, 1066, 1019, 989, and $415 \mathrm{~cm}^{-1}$ are assigned to 1 (Fig. 1, Fig. S1, Table 1 and Table S1, ESI $\dagger$ ). Another set of absorption bands located at $1477,1389,984$, and $801 \mathrm{~cm}^{-1}$ provides evidence for the presence of the allyl radical formed as a co-product of the thermal decomposition of 2 (Fig. 1c). The IR observed vibrational bands match well with the fundamentals of 1 (Table 1 and Table S1, ESI $\dagger$ ) computed anharmonically at the B3LYP/cc-pVTZ level of theory.

The UV/Vis spectrum of matrix isolated 1 reveals a strong absorption band at $\lambda_{\max }=295 \mathrm{~nm}$ (Fig. S2, ESI $\dagger$ ). It closely resembles the previously reported spectrum of $\mathbf{1}$ in the gas phase $^{23}$ and is in good agreement with its computed UV/Vis spectrum using time-dependent density functional theory (TD-DFT): TD-M06-2X/6-311++G(2d,2p) computations of the excitations exhibit two weak transitions at $310 \mathrm{~nm}(f=0.001)$ and $360 \mathrm{~nm}(f=0.0037)$ as well as two very intense transitions at $246 \mathrm{~nm}(f=0.0141)$ and $228 \mathrm{~nm}(f=0.1744)$, respectively.
Table 1 Experimental (Ar matrix, $10 \mathrm{~K}$ ) and computed anharmonic IR frequencies of 1 , band origins in $\mathrm{cm}^{-1}$, and computed intensities $\left(\mathrm{km} \mathrm{mol}^{-1}\right)$ in parentheses

\begin{tabular}{lllll}
\hline Mode & Computed $^{a}$ & $\mathrm{Ar}, 10 \mathrm{~K}^{b}$ & Sym. & Assignment (approx.) \\
\hline 25 & $1581(25)$ & $1553(\mathrm{~s})$ & $a_{1}$ & $\mathrm{C}=\mathrm{C}$ str \\
24 & $1565(4)$ & $1544(\mathrm{w})$ & $b_{2}$ & C=C str \\
23 & $1475(23)$ & $1433(\mathrm{~m})$ & $a_{1}$ & C-H def \\
22 & $1437(2)$ & $1419(\mathrm{w})$ & $b_{2}$ & C-H def \\
21 & $1336(0)$ & - & $b_{2}$ & C-H def \\
20 & $1257(1)$ & $1263(\mathrm{w})$ & $b_{2}$ & C=C str + C-H def \\
19 & $1190(1)$ & $1152(\mathrm{w})$ & $a_{1}$ & C-H def \\
18 & $1170(0)$ & - & $b_{2}$ & C-H def \\
17 & $1075(23)$ & $1066(\mathrm{~m})$ & $a_{1}$ & C-S str + ring distortion \\
16 & $1075(4)$ & - & $b_{2}$ & Ring distortion \\
15 & $1030(5)$ & $1019(\mathrm{~m})$ & $a_{1}$ & Ring distortion \\
14 & $999(0)$ & - & $b_{1}$ & C-H o.o.p. def \\
13 & $997(1)$ & $989(\mathrm{~m})$ & $a_{1}$ & Ring breathing \\
12 & $976(0)$ & - & $a_{2}$ & C-H o.o.p. def \\
11 & $896(2)$ & $908(\mathrm{w})$ & $b_{1}$ & C-H o.o.p. def \\
10 & $835(0)$ & - & $a_{2}$ & C-H o.o.p. def \\
9 & $738(42)$ & $750(\mathrm{~s})$ & $b_{1}$ & C-H o.o.p. def \\
8 & $701(30)$ & $670(\mathrm{~s})$ & $b_{1}$ & C-H o.o.p. def \\
7 & $699(8)$ & $662(\mathrm{w})$ & $a_{1}$ & C-S str + ring distortion \\
6 & $624(0)$ & - & $b_{2}$ & Ring distortion \\
5 & $475(8)$ & $451(\mathrm{w})$ & $b_{1}$ & Ring breathing \\
4 & $419(0)$ & - & $a_{2}$ & Ring breathing \\
3 & $408(0)$ & $415(\mathrm{w})$ & $a_{1}$ & Ring breathing
\end{tabular}

${ }^{a}$ UB3LYP/cc-pVTZ, anharmonic approximation, unscaled, intensities (in parentheses) in $\mathrm{km} \mathrm{mol}{ }^{-1} \cdot{ }^{b}$ Experiment: argon matrix, $10 \mathrm{~K}$; approximate relative intensities (w: weak, m: medium, s: strong).

At the UM06-2X/6-311++G(2d,2p) and UB3LYP/cc-pVTZ levels of theory the allylic C-S BDE energies of 2 are $58.7 \mathrm{kcal} \mathrm{mol}^{-1}$ and $48.4 \mathrm{kcal} \mathrm{mol}^{-1}$, whereas the BDE of the $\mathrm{S}-\mathrm{S}$ bond in 3 amounts to $64.8 \mathrm{kcal} \mathrm{mol}^{-1}$ and $56.5 \mathrm{kcal} \mathrm{mol}^{-1}$, respectively. In accord with earlier theoretical studies, ${ }^{45,46}$ the UM06-2X/ $6-311++G(2 d, 2 p)$ optimized geometry of 1 shows a planar structure with a ${ }^{2} \mathrm{~B}_{1}$ electronic ground state; the lowest excited state $\left({ }^{2} \mathrm{~B}_{2}\right)$ lies $7.3 \mathrm{kcal} \mathrm{mol}^{-1}$ higher at the CASPT2/6-311++G(3df,3pd) level (complete active space second-order perturbation theory), ${ }^{47}$ in excellent agreement with the experimental value of $7.4 \pm$ $0.2 \mathrm{kcal} \mathrm{mol}{ }^{-1}$. ${ }^{46}$ The $\mathrm{C}-\mathrm{S}$ bond of $1(1.756 \AA)$ is shorter than that in thiophenol $(1.772 \AA)$ at the same level of theory. No significant geometrical changes were observed in the phenyl ring in comparison with thiophenol (Fig. S3, ESI $\dagger$ ). This indicates that the unpaired electron spin is largely localized on the sulfur atom, in marked contrast to other highly delocalized aryl radicals such as the phenoxy and phenylaminyl radicals that both show significant spin delocalization over the ring as well. ${ }^{48}$
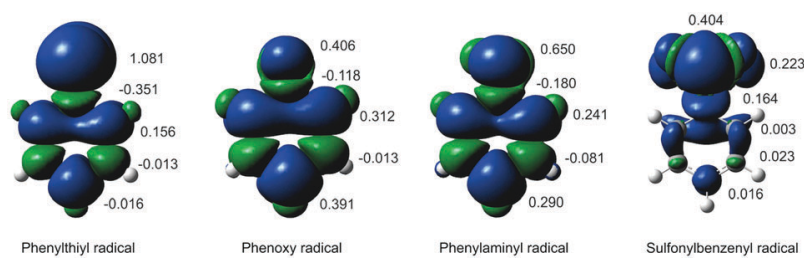

Fig. 2 Computed spin densities of 1, 4, 5, and the phenoxy - as well as the phenylaminyl radicals - at the UM06-2X/6-311++G(2d,2p) level of theory and a comparison with the phenoxy and phenylaminyl radicals (heteroatom at the top in all cases). 
This can be derived from the spin density distributions of these radicals (Fig. 2).

\section{Phenylthiyl peroxy radical 4}

We utilized 3 for the synthesis of $\mathbf{4}$ because 2 is less suitable as a precursor for $\mathbf{4}$ as the concomitantly formed allyl radical (6) reacts with molecular oxygen to give the allylperoxy radical. ${ }^{49}$ Doping argon matrices containing the products of the VFP of 3 with variable oxygen concentrations in the range of $0.1-2 \%$ resulted in significant changes in the IR spectra. Most notably, these changes occurred in the area of out-of-plane (o.o.p) $\mathrm{C}-\mathrm{H}$ vibration modes between 800 and $600 \mathrm{~cm}^{-1}$. New bands appeared and grew at 751 and $686 \mathrm{~cm}^{-1}$ by increasing the oxygen concentration and by annealing the matrix up to $35 \mathrm{~K}$ for several minutes (and re-cooling before measurement). In the presence of $\sim 1 \%$ of $\mathrm{O}_{2} 1$ is essentially quantitatively consumed.

According to our M06-2X/6-311G++G(2d,2p) and B3LYP/ cc-pVTZ computations, $\mathbf{4}$ displays two conformers, namely a gauche (4g) form and a slightly higher-lying trans (4t) form (Fig. S4, ESI $\dagger)$. The conformer $\mathbf{4 g}$ displays no symmetry $\left(C_{1}\right)$, whereas $\mathbf{4 t}$ shows $C_{\mathrm{s}}$ symmetry and has an ${ }^{2} \mathrm{~A}^{\prime \prime}$ electronic ground state. The experimental data indicate the presence of only one conformer (4g) in the argon matrix. At the M06-2X/6-311G++G(2d,2p) and B3LYP/cc-pVTZ levels, $4 \mathrm{~g}$ is 0.5 and $0.6 \mathrm{kcal} \mathrm{mol}^{-1}$ (including the zero point vibrational energy correction, ZPVE, denoted as $\left.\Delta H_{0}\right)$ more stable than conformer $4 \mathbf{t}$, respectively. The activation barrier for the $\mathbf{4 g} \rightarrow \mathbf{4 t}$ isomerisation is +0.9 and $+1.3 \mathrm{kcal} \mathrm{mol}^{-1}$ $\left(\Delta H_{0}\right)$, respectively (Fig. S4, ESI $\dagger$ ).

The new IR absorptions were assigned to 4 (Scheme 1 and Fig. 3); in highly diluted matrices $\left(0.1 \%\right.$ of $\left.\mathrm{O}_{2}\right)$, the monomers predominate. Annealing the matrices containing 1 and $\mathrm{O}_{2}$ (0.1-1\%) at temperatures above $30 \mathrm{~K}$ allows small trapped molecules to diffuse $\mathrm{s}^{50,51}$ and this results in an increase of bands of $\mathbf{4 g}$. In addition, dilution experiments allowed us to differentiate dimers from higher aggregates. The new bands appear only when both 1 and $\mathrm{O}_{2}$ are present in the matrix, and the band intensities increase if the concentration of one of the components increases. We therefore assigned these bands to the out-of-plane vibration (o.o.p.) $\mathrm{C}-\mathrm{H}$ modes $\nu_{8}$ and $\nu_{9}$ of $\mathbf{4 g}$. Moreover, the good agreement between the computed and experimental spectra of the isotopologues $\left(\mathrm{C}_{6} \mathrm{H}_{5} \mathrm{~S}^{18} \mathrm{O}_{2}\right)$ also confirms the successful preparation of 4 . For example, the strong IR band at $1173 \mathrm{~cm}^{-1}$ shows a strong isotope red shift by $64 \mathrm{~cm}^{-1}$ and is thus assigned to the $\mathrm{O}-\mathrm{O}$ stretch (computed at $1239 \mathrm{~cm}^{-1}$ ) of $\mathbf{4 g}$, in reasonable agreement with the calculated shift of $83 \mathrm{~cm}^{-1}$. Other medium and weak bands at 1442, 1310, 1279, 1090 and $475 \mathrm{~cm}^{-1}$ were also attributed to $4 \mathrm{~g}$. The unscaled UM06-2X/ 6-311++G(2d,2p) computed frequencies of the ${ }^{16} \mathrm{O}_{2}-\mathbf{4 g}$ and ${ }^{18} \mathrm{O}_{2}-4 \mathrm{~g}$ isotopologues agree well with the experimentally observed frequencies (Table S2, ESI $\dagger$ ). Similar to 4, the reaction of the phenyl radical with $\mathrm{O}_{2}$ was investigated using the matrix isolation technique. ${ }^{51}$ The reaction of alkyl radicals with oxygen analogously results in the formation of alkylperoxy radicals, which usually proceed without or with very low barriers. ${ }^{51-53}$

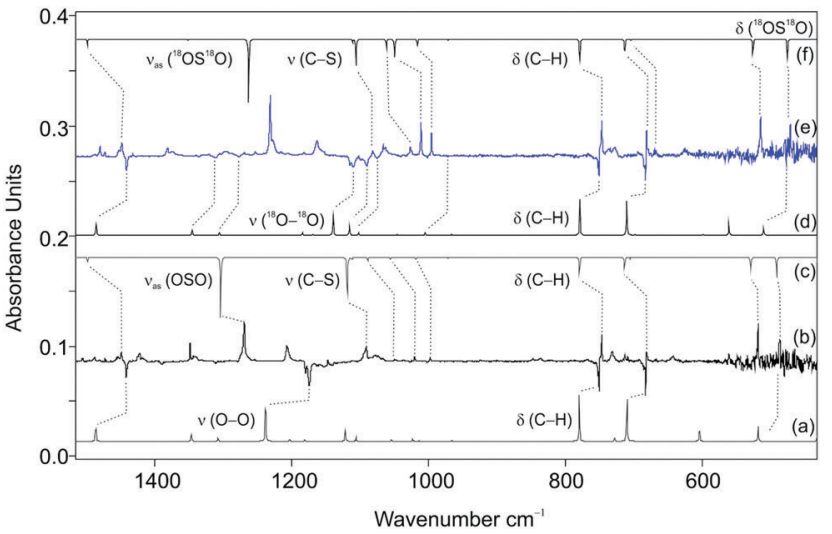

Fig. 3 (a) IR spectrum of 4 computed at M06-2X/6-311++G(2d,2p) (unscaled). (b) IR difference spectra showing the photochemistry of $\mathbf{4}$ after irradiation at $\lambda=465 \mathrm{~nm}$ in argon at $10 \mathrm{~K}$. Downward bands assigned to 4 disappear while upward bands assigned to 5 appear after $60 \mathrm{~s}$ of irradiation time. (c) IR spectrum of 5 computed at M06-2X/6-311++G(2d,2p) (unscaled). (d) IR spectrum of ${ }^{18} \mathrm{O}_{2}-4$ computed at M06-2X/6-311++G(2d,2p) (unscaled). (e) IR difference spectra showing the photochemistry of ${ }^{18} \mathrm{O}_{2}-\mathbf{4}$ after irradiation at $\lambda=465 \mathrm{~nm}$ in argon at $10 \mathrm{~K}$. Bands pointing downwards assigned to ${ }^{18} \mathrm{O}_{2}-\mathbf{4}$ disappear and bands pointing upwards assigned to ${ }^{18} \mathrm{O}_{2}-\mathbf{5}$ appear after $60 \mathrm{~s}$ of irradiation time. (f) IR spectrum of ${ }^{18} \mathrm{O}_{2}-\mathbf{5}$ computed at M06-2X/ $6-311++G(2 d, 2 p)$ (unscaled).

The fundamental question whether the formation of $\mathbf{4}$ by addition of molecular oxygen to $\mathbf{1}$ is an exothermic or endothermic process is not yet unambiguously answered by theory. The reported $\Delta E$ value computed at $\mathrm{BHLYP} / \mathrm{cc}-\mathrm{pVTZ}$ indicates a mildly exothermic process $\left(-7.9 \mathrm{kcal} \mathrm{mol}^{-1}\right)$ for the formation of 4. ${ }^{8}$ According to our M06-2X/6-311++G(2d,2p) and B3LYP/ cc-pVTZ computations, the reaction of 1 with molecular oxygen is also exothermic by $-7.6 \mathrm{kcal} \mathrm{mol}^{-1}$ and $-8.1 \mathrm{kcal} \mathrm{mol}^{-1}$ $\left(-6.0\right.$ and $\left.-6.9 \mathrm{kcal} \mathrm{mol}^{-1}, \Delta H_{0}\right)$; MP2/cc-pVDZ gives an exothermicity of $-5.9 \mathrm{kcal} \mathrm{mol}^{-1}$. As anticipated for an exothermic radical reaction, no transition state was found for the $\mathrm{C}_{6} \mathrm{H}_{5} \mathrm{~S}+{ }^{3} \mathrm{O}_{2} \rightarrow$ $\mathrm{C}_{6} \mathrm{H}_{5} \mathrm{SOO}$ addition. Similarly, no barrier could be located for the ${ }^{3} \mathrm{O}_{2}$ addition to the vinyl radical to produce the vinylperoxy radical. ${ }^{54}$ The formation of $\mathbf{4}$ in a thermal reaction at temperatures as low as $30 \mathrm{~K}$ in our matrix indicates a very small or no activation barrier for this reaction, in accordance with our theoretical assessment.

\section{Photochemistry of 4}

Irradiation of the matrix in the broad absorption band of 4 at $\lambda=465 \mathrm{~nm}$ resulted in the disappearance of all IR absorption bands assigned to 4 , and simultaneously, at least two distinct species formed during photolysis. The product distribution observed upon photodissociation of $\mathbf{4}$ depended markedly on the initial concentration of $\mathrm{O}_{2}$. Irradiation of the matrices obtained by co-condensation of pyrolysis products with an argon mixture containing $\sim 0.5-1 \%$ of $\mathrm{O}_{2}$ resulted in the appearance of IR bands at 1436, 1271, 1093, 1049, 1021, 997, $747,681,668,518$, and $487 \mathrm{~cm}^{-1}$ and these were attributed to 5 . A comparison of the computed (UM06-2X/6-311++G(2d,2p), 
unscaled) and experimental IR frequencies of two isotopically substituted radicals allowed their unambiguous identification (Table S3, ESI $\dagger$ ). In particular, we found a large ${ }^{18} \mathrm{O}$ isotope shift for a band at $1271 \mathrm{~cm}^{-1}$ (-39 $\mathrm{cm}^{-1}$ expt., $-41 \mathrm{~cm}^{-1}$ theor.), which was assigned to the OSO asymmetric vibration of 5. The experimental ${ }^{18} \mathrm{O}$ isotope shift of $-22 \mathrm{~cm}^{-1}$ was also observed for the OSO symmetric vibration, in reasonable agreement with a computed shift of $-28 \mathrm{~cm}^{-1}$. Furthermore, the expected band shifts were also observed for the OSO deformation vibration (an experimental shift of $-15 \mathrm{~cm}^{-1}$ and a theoretical shift of $-16 \mathrm{~cm}^{-1}$ ).

In accordance with earlier theoretical studies, ${ }^{8}$ the rearrangement of 4 to 5 is exothermic by $-61.9,-60.4$ and $-57.2 \mathrm{kcal} \mathrm{mol}^{-1}$ (M06-2X/6-311++G(2d,2p), B3LYP/cc-pVTZ, and MP2/cc-pVDZ $\Delta H_{0}$ ). The optimized geometry shows a planar $C_{\mathrm{s}}$ structure with a ${ }^{2} \mathrm{~A}^{\prime}$ electronic state, where the spin density is delocalized over the sulfonyl moiety (Fig. 2). The transformation process $4 \rightarrow \mathbf{5}$ through the transition state TS2 is associated with a barrier of +23.1 and $+25.2 \mathrm{kcal} \mathrm{mol}^{-1}$, respectively (M06-2X/6-311++G(2d,2p) and B3LYP/cc-pVTZ, $\Delta H_{0}$, Fig. S5, ESI $\dagger$ ).

\section{Conclusion}

The phenylthiyl radical 1 was synthesized by VFP of allylphenylsulfide and diphenylsulfide in argon and characterized using matrix isolation IR and UV/Vis spectroscopic methods. Radical 1 reacts with molecular triplet oxygen to form the hitherto unreported phenylthiyl peroxy radical $\mathbf{4}$ both in the gas phase and in argon matrices. The formation of $\mathbf{4}$ under matrix isolation conditions indicates that this reaction proceeds with a low or no activation barrier. Photolysis of a matrix of 4 with light at $\lambda=465 \mathrm{~nm}$ led to the formation of the considerably more stable phenylsulfonyl radical (5), which is also a novel species. The experimentally observed IR spectra are consistent with the spectra computed at the UM06-2X/6-311++G(2d,2p) and UB3LYP/cc-pVTZ levels of theory.

\section{Experimental details}

\section{Matrix apparatus design}

For the matrix isolation studies, we used an APD Cryogenics HC-2 cryostat with a closed-cycle refrigerator system, equipped with an inner CsI window for IR measurements. Spectra were recorded using a Bruker IFS 55 FT-IR spectrometer with a spectral range of $4500-400 \mathrm{~cm}^{-1}$ and a resolution of $0.7 \mathrm{~cm}^{-1}$, and UV/Vis spectra were recorded using a JASCO V-670 spectrophotometer. For the combination of vacuum flash pyrolysis with matrix isolation, we employed a small, home-built, water-cooled oven, which was directly connected to the vacuum shroud of the cryostat. The pyrolysis zone consisted of an empty quartz tube with an inner diameter of $8 \mathrm{~mm}$, which was resistively heated over a length of $50 \mathrm{~mm}$ by a coaxial wire. The temperature was monitored using a NiCr-Ni thermocouple. Allylphenylsulfide 2 and diphenylsulfide $\mathbf{3}$ (Sigma-Aldrich) were evaporated (2: $5{ }^{\circ} \mathrm{C}, 3: 60{ }^{\circ} \mathrm{C}$ ) from a storage bulb into the quartz pyrolysis tube. At a distance of approximately $50 \mathrm{~mm}$, all pyrolysis products were co-condensed with a large excess of argon (typically 60-120 mbar from a $2000 \mathrm{~mL}$ storage bulb) on the surface of the matrix window at $11 \mathrm{~K}$. Several experiments with pyrolysis temperatures ranging from 600 to $960{ }^{\circ} \mathrm{C}$ were performed in order to determine the optimal pyrolysis conditions. A high-pressure mercury lamp (HBO 200, Osram) with a monochromator (Bausch \& Lomb) was used for irradiation.

\section{Computations}

All geometries were optimized and characterized as minima or transition structures by means of analytical harmonic vibrational frequency computations at the M06-2X/6-311++G(3d,3p), B3LYP/ cc-pVTZ, and MP2/cc-pVDZ levels of theory (for more details, refer to the ESI $\dagger){ }^{55-58}$ All computations were performed using the Gaussian09 program. ${ }^{59}$

\section{Acknowledgements}

This paper is dedicated to Prof. Grzegorz Mloston (Lodz University) for his seminal contributions to organic sulfur chemistry. This work was supported by the Deutsche Forschungsgemeinschaft (Schr 597/19-1).

\section{Notes and references}

1 F. Dénès, M. Pichowicz, G. Povie and P. Renaud, Chem. Rev., 2014, 114, 2587-2693.

2 T. Hashimoto, Y. Kawamata and K. Maruoka, Nat. Chem., 2014, 6, 702-705.

3 M. Kolberg, K. R. Strand, P. Graff and K. Kristoffer Andersson, Biochim. Biophys. Acta, Proteins Proteomics, 2004, 1699, 1-34.

4 E. Torrents, P. Aloy, I. Gibert and F. Rodríguez-Trelles, J. Mol. Evol., 2002, 55, 138-152.

5 J. S. Lim, Y. S. Lee and S. K. Kim, Angew. Chem., Int. Ed., 2008, 47, 1853-1856.

6 G. A. Amaral, F. Ausfelder, J. G. Izquierdo, L. Rubio-Lago and L. Bañares, J. Chem. Phys., 2007, 126, 024301.

7 O. Ito, Res. Chem. Intermed., 1995, 21, 69-93.

8 K. J. Tan and U. Wille, Chem. Commun., 2008, 6239-6241.

9 V. T. D'Souza, R. Nanjundiah, J. Baeza H and H. H. Szmant, J. Org. Chem., 1987, 52, 1720-1725.

10 V. T. D’Souza, V. K. Iyer and H. H. Szmant, J. Org. Chem., 1987, 52, 1725-1728.

11 M. I. Chung, V. T. D’Souza and H. H. Szmant, J. Org. Chem., 1987, 52, 1741-1744.

12 D. F. Taber, G. J. Gorski, L. M. Liable-Sands and A. L. Rheingold, Tetrahedron Lett., 1997, 38, 6317-6318.

13 O. Ito, R. Omori and M. Matsuda, J. Am. Chem. Soc., 1982, 104, 3934-3937.

14 O. Ito and M. Matsuda, J. Phys. Chem., 1984, 88, 1002-1005. 15 O. Ito and M. Matsuda, J. Org. Chem., 1984, 49, 17-20.

16 O. Ito and M. Matsuda, J. Am. Chem. Soc., 1982, 104, 1701-1703.

17 O. Ito and M. Matsuda, J. Am. Chem. Soc., 1981, 103, 5871-5874. 
18 O. Ito and M. Matsuda, J. Am. Chem. Soc., 1979, 101, 1815-1819.

19 O. Ito, Y. Arito and M. Matsuda, J. Chem. Soc., Perkin Trans. 2, 1988, 869-873.

20 L. Wang and P. E. Floreancig, Org. Lett., 2004, 6, 569-572.

21 S. Knapp, M. R. Madduru, Z. Lu, G. J. Morriello, T. J. Emge and G. A. Doss, Org. Lett., 2001, 3, 3583-3585.

22 I. Reva, M. J. Nowak, L. Lapinski and R. Fausto, Phys. Chem. Chem. Phys., 2015, 17, 4888-4898.

23 G. Porter and F. J. Wright, Trans. Faraday Soc., 1955, 51, 1469-1474.

24 M. Bonifacic, J. Weiss, S. A. Chaudhri and K. D. Asmus, J. Phys. Chem., 1985, 89, 3910-3914.

25 G. N. R. Tripathi, Q. Sun, D. A. Armstrong, D. M. Chipman and R. H. Schuler, J. Phys. Chem., 1992, 96, 5344-5350.

26 P. J. Zandstra and J. D. Michaelsen, J. Chem. Phys., 1963, 39, 933-938.

27 U. Schmidt, Angew. Chem., Int. Ed., 1964, 3, 602-608.

28 F. G. Bordwell, X.-M. Zhang, A. V. Satish and J. P. Cheng, J. Am. Chem. Soc., 1994, 116, 6605-6610.

29 D. A. Armstrong, Q. Sun and R. H. Schuler, J. Phys. Chem., 1996, 100, 9892-9899.

30 R. M. Borges dos Santos, V. S. F. Muralha, C. F. Correia, R. C. Guedes, B. J. Costa Cabral and J. A. Martinho Simões, J. Phys. Chem. A, 2002, 106, 9883-9889.

31 A. K. Chandra, P.-C. Nam and M. T. Nguyen, J. Phys. Chem. A, 2003, 107, 9182-9188.

32 H. P. Reisenauer, P. R. Schreiner, J. Romanski and G. Mloston, J. Phys. Chem. A, 2015, 119, 2211-2216.

33 H. P. Reisenauer, J. Romanski, G. Mloston and P. R. Schreiner, Chem. Commun., 2013, 49, 9467-9469.

34 R. J. Charlson, J. E. Lovelock, M. O. Andreae and S. G. Warren, Nature, 1987, 326, 655-661.

35 M. O. Andreae, C. D. Jones and P. M. Cox, Nature, 2005, 435, 1187-1190.

36 I. Faloona, Atmos. Environ., 2009, 43, 2841-2854.

37 A. A. Turnipseed, S. B. Barone and A. R. Ravishankara, J. Phys. Chem., 1992, 96, 7502-7505.

38 J. Mönig, K.-D. Asmus, L. G. Forni and R. L. Willson, Int. J. Radiat. Biol., 1987, 52, 589-602.

39 M. Tamba, G. Simone and M. Quintiliani, Int. J. Radiat. Biol., 1986, 50, 595-600.
40 M. D. Sevilla, D. Becker and M. Yan, Int. J. Radiat. Biol., 1990, 57, 65-81.

41 D. Becker, S. Swarts, M. Champagne and M. D. Sevilla, Int. J. Radiat. Biol., 1988, 53, 767-786.

42 S. G. Swarts, D. Becker, S. DeBolt and M. D. Sevilla, J. Phys. Chem., 1989, 93, 155-161.

43 X. Zhang, N. Zhang, H.-P. Schuchmann and C. von Sonntag, J. Phys. Chem., 1994, 98, 6541-6547.

44 S. Jagannathan, J. R. Cooper and C. L. Wilkins, Appl. Spectrosc., 1989, 43, 781-786.

45 P. Mulder, O. Mozenson, S. Lin, C. E. S. Bernardes, M. E. Minas da Piedade, A. F. L. O. M. Santos, M. A. V. Ribeiro da Silva, G. A. DiLabio, H.-G. Korth and K. U. Ingold, J. Phys. Chem. A, 2006, 110, 9949-9958.

46 J. S. Lim, I. S. Lim, K.-S. Lee, D.-S. Ahn, Y. S. Lee and S. K. Kim, Angew. Chem., Int. Ed., 2006, 45, 6290-6293.

47 J. S. Lim, H. Choi, I. S. Lim, S. B. Park, Y. S. Lee and S. K. Kim, J. Phys. Chem. A, 2009, 113, 10410-10416.

48 R. Crespo-Otero, K. Bravo-Rodriguez, S. Roy, T. Benighaus, W. Thiel, W. Sander and E. Sánchez-García, ChemPhysChem, 2013, 14, 805-811.

49 E. G. Baskir and O. M. Nefedov, Russ. Chem. Bull., 1996, 45, 99-106.

50 A. Mardyukov and W. Sander, Eur. J. Org. Chem., 2010, 2904-2909.

51 A. Mardyukov and W. Sander, Chem. - Eur. J., 2009, 15, 1462-1467.

52 S. Nandi, S. J. Blanksby, X. Zhang, M. R. Nimlos, D. C. Dayton and G. B. Ellison, J. Phys. Chem. A, 2002, 106, 7547-7556.

53 E. B. Jochnowitz, X. Zhang, M. R. Nimlos, B. A. Flowers, J. F. Stanton and G. B. Ellison, J. Phys. Chem. A, 2010, 114, 1498-1507.

54 A. M. Mebel, E. W. G. Diau, M. C. Lin and K. Morokuma, J. Am. Chem. Soc., 1996, 118, 9759-9771.

55 Y. Zhao and D. G. Truhlar, Theor. Chem. Acc., 2008, 120, 215-241.

56 A. D. Becke, Phys. Rev. A: At., Mol., Opt. Phys., 1988, 38, 3098-3100.

57 C. Lee, W. Yang and R. G. Parr, Phys. Rev. B: Condens. Matter Mater. Phys., 1988, 37, 785-789.

58 B. Miehlich, A. Savin, H. Stoll and H. Preuss, Chem. Phys. Lett., 1989, 157, 200-206.

59 M. J. Frisch, et al., Wallingford CT, 2013. 